\title{
Tentativas de suicídio e profissionais de saúde: significados possíveis
}

\section{Suicide attempts and health professionals: possible meanings \\ Los intentos de suicidio y los profesionales de la salud: posibles significados}

\author{
Ana Paula Araújo de Freitas* \\ Universidade Federal de Santa Catarina - UFSC, Florianópolis, Santa Catarina, \\ Brasil
}

\author{
Lucienne Martins Borges** \\ Universidade Federal de Santa Catarina - UFSC, Florianópolis, Santa Catarina, \\ Brasil
}

\begin{abstract}
RESUMO
Este estudo, de caráter qualitativo, teve como objetivo identificar os significados atribuídos por profissionais de saúde, que atuam em urgências e emergências hospitalares, às tentativas de suicídio. Foram entrevistados 16 profissionais de dois serviços de urgência e dois de emergência de um município do sul do Brasil. Os resultados mostraram a construção dos significados com base em dois polos. O primeiro entende o suicídio como condição de sofrimento que leva a uma conduta acolhedora. Já o segundo pontua o sofrimento, porém considera a demanda não legítima aos contextos pesquisados. Evidenciou-se a necessidade de espaços de discussão sobre o suicídio nos cursos da área da Saúde, bem como atividades de educação permanente que trabalhem o manejo clínico, qualificando assim a prática.
\end{abstract}

Palavras-chave: tentativa de suicídio, profissionais de saúde, urgências, emergências hospitalares.

\begin{abstract}
This study, qualitative, aimed to identify the meanings attributed to suicide attempts by health professionals working in emergency rooms and hospital emergencies. Were interviewed sixteen professionals of two urgencies and two hospital emergencies of a city from south Brazil. The results showed the construction of meanings from two poles. The first considers suicide as a condition of suffering that leads to a cozy conduct. The second punctuates the suffering, but do not consider the legitimate demand to the contexts surveyed. Evidenced the need for spaces for discussion of suicide in courses in the area of health and education activities ongoing working clinical management, thus qualifying practice.
\end{abstract}

Keywords: suicide attempts, health professionals, urgencies, hospital emergencies. 


\begin{abstract}
RESUMEN
Este estudio cualitativo, tuvo como objetivo identificar los significados atribuidos por parte de los profesionales de salud, que trabajan en las salas de urgencias y emergencias hospitalarias, a los intentos de suicidio. Se entrevistó a 16 profesionales en dos departamentos de emergencia y dos de emergencia un municipio en el sur de Brasil. Los resultados muestran la construcción de los significados sobre la base de dos polos. La primera considera el suicidio como una condición de sufrimiento que lleva a una conducta acogedor. La segunda señala el sufrimiento, pero no tienen en cuenta la demanda legítima de los contextos estudiados. Lo demuestra la necesidad de espacios para la discusión de suicidio en los cursos en el área de las actividades de salud y educación de gestión clínica de trabajo en curso, así calificando la práctica.
\end{abstract}

Palabras-clave: intento de suicidio, profesionales de la salud, urgencias, emergencias hospitalarias.

\title{
1 I ntrodução
}

Nas últimas décadas, é consenso entre os pesquisadores que o suicídio é uma questão de saúde pública (Brasil, 2006; Bertolote \& Fleischmann, 2002b; Botega, Werlang, Cais, \& Macedo, 2006; OMS, 2000). No ano de 2002, o suicídio representava $1,8 \%$ do total de custos com doenças no mundo todo. Para o ano de 2020, estima-se que esta porcentagem aumente para 2,4\% (Brasil, 2009).

Além do impacto no sistema de saúde, sabe-se, por exemplo, que, no contexto familiar e social, um único suicídio afeta diretamente no mínimo outras seis pessoas e que, quando ocorrido em lugares públicos como em escolas, tem impacto sobre centenas de pessoas (OMS, 2000). Em números, para cada suicídio, acredita-se que de 10 a 20 tentativas são praticadas (Brasil, 2006).

O suicídio pode ser definido como o "ato humano de causar a cessação da própria vida" (Brasil, 2009, p.40) e a tentativa de suicídio como o "ato de tentar cessar a própria vida, porém, sem consumação" (Brasil, 2009, p.40). Dada a sua complexidade, é compreendido como um fenômeno multidimensional, resultado da interação de diferentes fatores desde os ambientais e sociais até os genéticos, biológicos e fisiológicos (OMS, 2000), que assume significados diversos que variam conforme a subjetividade de cada pessoa.

Em decorrência do aumento do número de casos, o suicídio, assim como as suas tentativas estão cada vez mais presentes no cotidiano de trabalho dos profissionais de saúde, em particular dos que atuam em urgências e emergências. É para estes locais que os pacientes que tentaram suicídio são levados para atendimento, quando algum socorro ainda é possível.

Porém, lidar com pacientes que chegam por tentativa de suicídio não é uma tarefa fácil. A literatura aponta que é comum o uso de crenças 
pessoais, por parte de membros da equipe de saúde, na tentativa de ajudar os pacientes. Estes podem gerar sentimentos ambivalentes nos profissionais, que, de um lado, buscam estar atentos à escuta das demandas dos pacientes - que nem sempre é a de viver - mas, por outro, precisam tomar todas as medidas necessárias a fim de que a pessoa não concretize o ato (Bertolote, Mello-Santos, \& Botega, 2010).

Ainda, é possível afirmar que parte dos profissionais de saúde resiste em atender às demandas entendidas por eles como de saúde mental, em hospitais gerais. Estudos mostram que profissionais de saúde mental sentem-se mais mobilizados e têm atitude mais positiva para com os pacientes que tentaram suicídio do que aqueles que não atuam na área (Kishi, Kurosawa, Morimura, Hatta, \& Thurber, 2011; Srivastava \& Tiwari, 2012). O mesmo observou-se quando comparados dois hospitais, um deles hospital psiquiátrico e outro, hospital geral. Embora os profissionais de ambos os serviços demonstrem a tendência de considerar os pacientes que tentam suicídio de forma positiva e com simpatia, no hospital geral foram expressas atitudes mais negativas junto a esses pacientes que no hospital psiquiátrico (Suokas, Suominen, \& Lönnqvist, 2008).

Crepaldi (2012) pontua que quem tenta suicídio e é atendido nos serviços de saúde, em geral é recebido com revolta e agressividade por parte dos profissionais que prestam assistência, pois "esses não podem compreender como.... [o suicídio] acontece e, na maioria das vezes, não estão preparados para lidar com tal sofrimento e com a angústia que... [este] neles suscita" (p.15). A equipe se sente fracassada, uma vez que preparada profissionalmente para "curar", vê-se impossibilitada de realizar seu trabalho quando a morte é apontada como uma solução, sendo sua frustração e impotência expressas por uma postura de afastamento e rejeição ao usuário.

Porém, a qualidade do atendimento é fator importante na reabilitação e na recidiva de tentativas, qualidade esta perpassada pelos significados atribuídos pelos profissionais. Reiterando a importância da significação na prática profissional, pressupõe-se que "o profissional da área de saúde... deve ter em mente que está diante de um indivíduo semelhante a ele, mas também está diante de um sujeito diferente com características, peculiaridades e contexto situacional próprio" (Werlang, Macedo, \& Asnis, 2005, p.195).

Dessa forma, tendo em vista o atendimento às tentativas de suicídio nos serviços de urgência e emergência, este artigo se propõe a investigar o significado atribuído às tentativas de suicídio pelos profissionais que as atendem, nos contextos acima citados. O método utilizado permitiu a construção de três subcategorias de significados, as quais evidenciaram um complexo tecido semântico sobre como os profissionais têm compreendido a temática. 


\section{Método}

Participantes:

Participaram desta pesquisa dezesseis (16) profissionais de saúde, entre os quais 4 (quatro) médicos, 4 (quatro) assistentes sociais, 4 (quatro) enfermeiros, e 4 (quatro) psicólogos. Entre os participantes, metade trabalhava em serviços de urgência (Unidades de Pronto Atendimento - UPAs) e os demais em serviços de emergência hospitalar (hospitais gerais) de uma cidade da região sul do Brasil. Em virtude da realização desta pesquisa nos dois contextos acima citados, entende-se como urgência o imprevisto de agravo à saúde no qual não há necessariamente risco de vida, porém há a necessidade de assistência médica imediata. Por emergências entendem-se as situações em que há a constatação médica de agravo à saúde, com risco de vida ou sofrimento intenso, demandando tratamento médico imediato (Resolução no 1451, 1995).

A idade dos participantes variou entre 25 e 50 anos, cuja média foi 33 anos, sendo 12 (doze) deles do sexo feminino e 4 (quatro) do sexo masculino. A média de tempo em exercício da profissão foi de aproximadamente 9 (nove) anos, sendo o menor tempo igual a 8 (oito) meses e o mais longo igual a 27 (vinte e sete) anos. O tempo de trabalho em urgência ou emergência variou de 8 (oito) meses a 29 (vinte e nove) anos, cuja média foi de 5 anos de atuação nestes contextos.

Os critérios de inclusão adotados foram a) a atuação no atendimento às tentativas de suicídio, nos serviços de urgência e emergência hospitalares, no momento da pesquisa e b) a experiência no atendimento às tentativas de suicídio em sua prática profissional. $\mathrm{O}$ número de participantes foi definido pelo critério da saturação teórica dos dados. A partir da décima entrevista observou-se regularidade nos conteúdos trazidos pelos participantes, contudo optou-se pelo convite a mais profissionais a fim de permitir que outros significados ainda não contemplados pudessem aparecer, mesmo que em número pouco significativo (Guest, Bunce, \& Johnson, 2006; Santos \& Moré, 2011, Wanderbroocke \& Moré, 2012).

Instrumentos:

Por se tratar de um estudo de caráter qualitativo, o acesso às informações deu-se por meio de entrevistas. Foi elaborado um roteiro composto por 14 questões que nortearam o discurso do participante sem, contudo, impedir a livre verbalização a respeito do tema pesquisado. As questões 1, 2, 7, 9 e 13 investigaram especificamente os significados atribuídos pelos profissionais às tentativas de suicídio 
cometidas pelos pacientes atendidos, permitindo a construção da categoria 1, apresentada nos resultados.

As demais questões buscaram investigar a prática profissional dos participantes junto aos pacientes (categoria Acolhimento), as rotinas de atendimento, facilidades e dificuldades observadas (categoria Atendimento) e os encaminhamentos após a alta (categoria Encaminhamentos), porém a apresentação destas não está contemplada nos objetivos deste artigo.

Procedimentos:

A coleta dos dados foi realizada entre os meses de maio e julho de 2013. Num primeiro momento, foi realizado contato com as instituições - Secretaria Municipal de Saúde, Secretaria de Estado da Saúde e um hospital geral para informar a autorização da pesquisa pelo Comitê de Ética em Pesquisa com Seres Humanos (Parecer no 275.875 , de 13/05/2013) e solicitar a realização da mesma nos locais escolhidos. Na sequência, realizou-se contato com profissionais que atuavam nas urgências e emergências e o convite para participar da pesquisa. Este se deu via contato telefônico, momento no qual foram explicados os objetivos e procedimentos da pesquisa e foi agendado dia, horário e local para a realização da entrevista.

As entrevistas aconteceram nos respectivos locais de trabalho dos participantes, nos turnos da manhã, tarde e noite, sendo a maior parte delas realizada no período noturno, com duração média de 20 minutos. Todas as falas foram gravadas (após o consentimento do participante) e, posteriormente, transcritas. Para a elaboração da pesquisa, ressalta-se que foram respeitadas as orientações éticas consonantes à Resolução 196 que regulamenta as pesquisas com seres humanos (Resolução 196, 1996).

Análise de dados:

Ao término das entrevistas, o material obtido foi transcrito para a utilização do programa Atlas/Ti $5.0^{\circledR}$, um software que trata e analisa dados qualitativos, que organiza e sistematiza uma grande quantidade de material (Muhr, 2004). A primeira parte da análise consistiu na leitura exaustiva das narrativas, a fim de realizar o que Strauss e Corbin (2008) apresentam como codificação aberta, processo no qual "os conceitos são identificados e suas propriedades e dimensões são descobertas nos dados" (p.103). Em seguida, procedeu-se à codificação axial, definida como "o processo de relacionar categorias às suas subcategorias" ( $p .123)$, chegando assim às respostas aos objetivos desta pesquisa (Strauss \& Corbin, 2008), conforme apresentadas nos resultados, a seguir. 


\section{Resultados e discussão}

O significado que os profissionais de saúde atribuem às tentativas de suicídio por eles atendidas foi organizado com base em três subcategorias: 1. Definição de suicídio, 2. O que os profissionais pensam sobre o suicídio e 3 . Motivos pelos quais as pessoas tentam suicídio, apresentadas a seguir.

Subcategoria 1. Definição de suicídio

Para os participantes, identificados a partir de agora como P1, P2, P3... P16, o suicídio é definido como acabar com a vida, chamar a atenção e dar fim ao sofrimento. Em acabar com a vida, observa-se um conceito para o suicídio que contempla o agir contra si mesmo, de autoagressão, cujo resultado é tirar a própria vida. Nas palavras de P3, "suicídio é uma tentativa de terminar com a própria vida". Este conceito, apontado por quinze participantes, é semelhante ao conceito descrito pelos dicionários, que define o suicídio como "ato ou efeito de suicidar-se", e suicidar-se como "pôr termo à vida, matarse" (Houaiss \& Villar, 2009, p.1787).

O suicídio também é definido como uma forma de dar fim ao sofrimento. Para P5, há "um sofrimento psíquico tão grande que a pessoa decide, pra mim ela tá sofrendo tanto que ela decide terminar com a sua vida para acabar com esse sofrimento". Na fala do participante, o suicídio é relacionado à presença de um sofrimento a que se quer dar fim. Logo, é sinônimo de dar fim ao sofrimento, portanto uma definição que, ao mesmo tempo, motiva a ação do paciente.

E, por último, o suicídio é definido como uma tentativa de chamar a atenção. Para P14,

“É porque pra mim claramente temos duas situações, temos o suicídio e temos a tentativa de chamar atenção. O suicídio é geralmente uma depressão importante, uma falta de perspectiva, de qualquer possibilidade de futuro, ou de resolução de problema agudo que parece grande demais que ele não vai conseguir ultrapassar, falta de esperança".

Ainda que se considere o suicídio como o ato de atentar contra a própria vida, quando o fenômeno é apontado como chamar a atenção, passa a ser definido com base em sua "função", situação esta que traz consequências importantes para a prática profissional. Silva e Boemer (2004), em estudo realizado também com profissionais de saúde, mostram que "a tentativa de suicídio consiste, [...] num gesto calculado para impressionar, assustar, ou forçar 
pessoas com quem o paciente está em contato a dar-lhe atenção e prestar-Ihe favores" (p.148).

\section{Subcategoria 2: "O que os profissionais pensam sobre o suicídio"}

Esta subcategoria reúne o que pensam os profissionais de saúde sobre o suicídio baseado em seis elementos de análise: demanda para a Saúde Pública, ausência de solução, ato de coragem, conhecimento sobre os métodos utilizados, o inverso da morte e fragilidade da rede de apoio e de atenção. Os dados demonstram a preocupação com um fenômeno que tem crescido nas últimas décadas, conforme apontado por P6, abaixo.

“... que é um problema de saúde pública, que cada vez tá mais, que a gente encontra mais casos, que a gente percebe mais casos e que como qualquer outro tipo de doença ou de problema que a gente acaba cuidando, que a gente acaba se deparando, é mais um deles".

Destaca-se a corroboração dos dados para os quais o Ministério da Saúde (Brasil, 2006) e a OMS (Bertolote \& Fleischmamm, 2002a) têm alertado, ou seja, o aumento do número de casos de suicídio e também de tentativas. Segundo a OMS, a estimativa para o ano de 2020 é que 1,5 milhão de pessoas morra por suicídio e um número 10 a 20 vezes maior de tentativas sejam praticadas (Bertolote \& Fleischmamm, 2002b).

Esta demanda e seu consequente aumento têm sido percebidos pelos profissionais de saúde e requerem, além da utilização de recursos técnicos para seu atendimento, sua legitimação como demanda de saúde e que, de alguma forma, precisa ser atendida. É importante lembrar não apenas as mudanças da noção de saúde ocorridas nos últimos anos, que incorporam esferas mais amplas ao conceito, mas, também as noções de humanização e integralidade, que balizam o Sistema Único de Saúde brasileiro (Maliska \& Wallauer, 2012).

Os participantes também pensam no suicídio como uma situação para a qual o paciente não enxerga outra solução, apresentada como ausência de solução. Este elemento de análise reúne conteúdos que destacaram o sofrimento, a falta de perspectiva e de alternativas e o suicídio como única solução vislumbrada pelo paciente. Conforme P8, “... é um fenômeno no qual a pessoa tem um sofrimento muito grande, na minha prática o que eu identifico é um sofrimento muito grande, onde a pessoa não consegue ver uma alternativa para dar solução a tal sofrimento".

A existência de um sofrimento e a ausência de solução para o mesmo são destaques no trecho acima, para o qual não se enxerga alternativa ou outras saídas que não seja tirar a própria vida. Ramos 
e Falcão (2011) trazem dados que validam o que foi mostrado. Segundo os autores, $60 \%$ dos participantes de uma pesquisa sobre Suicídio e Formação Médica afirmam que o suicídio está associado a muito sofrimento e desesperança. Entender o suicídio como um ato de coragem também esteve presente nas falas dos participantes. Para P4,

“... é um ato de extrema coragem. Eu já parei pra pensar nisso algumas vezes, quando a gente, é corriqueiro a gente atender pacientes nessa situação, então muitas vezes é um ato de extrema coragem, porque para a pessoa realmente fazer isso, realmente tentar dar fim à sua vida, é algo que ela deve estar sofrendo muito, como eu já te falei, pra ela tentar tá fazendo isso".

Aqui, as pessoas que tentam suicídio são percebidas como pessoas corajosas, porque conseguiram agir contra suas próprias vidas para acabar com um sofrimento. Dada sua multicausalidade, diversas são as formas de explicar o suicídio, sejam estas explicações acadêmicas ou não e pensar em termos como coragem ou covardia é o exemplo de uma delas. Contudo, conforme apontam Ramos e Falcão (2011), é preciso atentar para a tendência da reprovação, condenação ou até mesmo aprovação do suicídio, uma vez que ao contexto médico ou de emergência não cabe culpar ou condenar, cabe diagnosticar e ajudar o paciente em suas necessidades.

Ainda, os pacientes que tentam suicídio têm pouco conhecimento sobre os métodos utilizados para tirar a vida. De acordo com P3, "eles não buscam uma forma eficaz, a forma mais comum é intoxicação por algum produto químico em dose inadequada para alcançar o que eles querem ou o tipo de remédio que não é tóxico, dose não tóxica".

Os profissionais apontam que os pacientes comumente fazem uso de doses baixas ou inadequadas para que o método utilizado, sejam medicamentos, sejam substâncias químicas de fácil acesso como produtos de limpeza, cause algum dano sério à saúde ou provoque a morte. Esta informação permite questionar o que este paciente está buscando sinalizar, uma vez que o que também foi observado é que eles procuram o inverso da morte. P9 observa que:

“Eu já atendi pessoas que depois que passou se arrependeram, ficaram assustadas com a possibilidade de realmente ter morrido porque não penso que seja a morte concreta que elas buscam, eu acho que naquele momento, o que eu penso é que eles não conseguem pensar assim na morte, eles morrendo, enterro, às vezes até podem imaginar, mas é muito mais uma 
forma de parar a dor, tipo "não dá, chega, eu não aguento mais".

Observou-se que a pessoa não busca uma morte física, cujas decorrências práticas abarcariam rituais fúnebres e de despedida, velório, enterro e caixão, mas sim uma morte simbólica, um morrer que as faça renascer para uma vida diferente, uma vida sem sofrimento. Freud já dizia que a morte não tem representação no inconsciente, logo não pode ser desejada, pois ninguém deseja aquilo que não conhece (Maliska \& Wallauer, 2012).

Outra característica importante é o arrependimento do paciente após a tentativa. Tais informações vão ao encontro do estudo realizado por Botega et al (2005), que mostrou que apenas $25 \%$ das pessoas que tentaram suicídio queriam realmente morrer, sendo mais presente 0 desejo de dormir ou de se afastar dos problemas, ficando clara uma baixa intencionalidade de morte. Ainda, o mesmo estudo permite pensar que o suicídio acaba sendo utilizado como uma forma de solução de problemas, conforme apontado acima e que a morte em si não é o fim esperado.

E por fim, os profissionais observam uma fragilidade da rede de apoio e de atenção à pessoa, tanto de familiares como das instituições que atuam nas diferentes políticas públicas, sejam elas saúde, assistência social etc., como aponta P3:

“Enfim, eu acredito que são pessoas que precisam de acompanhamento e elas desistem e os profissionais também desistem delas. Pessoas que até então não foram acolhidas, muitas das vezes, e de repente não tem uma rede de serviço que realmente consiga acolher e resolver as questões. Isso de todas as políticas, não só a saúde, enfim..."

(Obs.: em caso de transcrição de fala oral, não é necessário escrever-se ao pé da letra, haja vista que o texto pode ficar incompreensível para o leitor, ok?)

Tais fragilidades estão presentes em duas esferas: a fragilidade na rede de apoio do paciente, que muitas vezes é uma pessoa que vive só, que não tem a rede de apoio próxima ou esta rede é distante, e a fragilidade da rede institucional para acolher a demanda do paciente, seja de acesso às unidades de saúde, como, por exemplo, dificuldades para agendar consultas, de acesso aos profissionais de saúde mental, para os quais há fila de espera para atendimento ou a outras políticas que se fizerem necessárias como a política de Assistência Social.

Bertolote et al. (2010) afirmam que uma tentativa de suicídio é um grito de socorro que pode ou não dar certo. Se der certo, provocará um movimento centrípeto, de aproximação e reestruturação; mas, se 
der errado, poderá ser fonte de mais agressões, tanto por parte da família ou da rede de apoio mais próxima, quanto de profissionais da rede, os quais não estejam preparados para lidar com esta demanda.

Subcategoria 1.3 "Motivos pelos quais as pessoas tentam suicídio"

Esta subcategoria reúne o que os participantes expressam como motivos pelos quais os pacientes cometem suicídio. Os principais motivos apontados foram dar uma solução ao sofrimento, a fragilidade dos recursos psíquicos do paciente, chamar a atenção de outrem, a falta de perspectivas para o futuro, a presença de conflitos conjugais, a presença de conflitos familiares, a pessoa considerar a tentativa ou sua morte um alívio para os outros e a presença de transtornos mentais.

O principal motivo observado é que a pessoa que tenta suicídio está buscando uma solução ao sofrimento. Para P5, "você percebe que não, tem toda uma história de vida e de dificuldades, enfim, ao longo da vida que levaram a esse momento as coisas chegarem nesse ponto". Já P3 entende que:

“... logo após uma briga, elas já não vinham bem aí tem um estressor naquele momento, que não é a causa, mas elas já estavam em intenso sofrimento, acontece algo que aí confirma ainda mais, "realmente, eu sou um peso, eu não sirvo pra nada" ou sei lá "esse casamento é horrível, minha vida é horrível e não vai mudar nunca". (P3)

É expressivo que a quase totalidade dos participantes tenha apontado que as pessoas que tentam suicídio encontram-se numa condição de sofrimento psíquico presente há muito tempo. Segundo elas, há uma história de vida e de dificuldades, em diferentes esferas da vida da pessoa, que, na presença de um estressor, pode desencadear a tentativa, conforme aponta P3. Este estressor não é a causa em si, mas sim o limite deste sofrer. Ainda, estas pessoas não enxergam outra maneira de solucionar seus problemas ou seu sofrimento, aproximando-se do que outros participantes trouxeram sobre o que pensam sobre o suicídio, quando apontam que a pessoa não vê outra solução.

Outro motivo pelos quais as pessoas tentam suicídio é a fragilidade dos recursos psíquicos. P4 afirma que

“... então você vê realmente que existem histórias de sofrimento que não é de agora, que é de uma história de vida, que demonstra uma vulnerabilidade psíquica enorme e que são pessoas muito vulneráveis a qualquer coisa, qualquer fracasso". A fala de P6 vai nessa mesma direção, quando pontua que "eu 
só consigo responder intenso sofrimento emocional e uma estratégia disfuncional pra tentar aliviar isso por falta de recursos".

Entre as características apontadas, destaca-se a falta de recursos psíquicos para lidar com as dificuldades e o uso de estratégias disfuncionais frente aos problemas do dia a dia, observadas nas falas acima. Já o participante P1 ilustra em sua fala a rigidez de pensamento, quando afirma "tudo ou nada, aquela coisa assim, ah não, se é isso então agora não dá mais". O Manual de Prevenção do Suicídio do Ministério da Saúde (Brasil, 2006) aponta três principais aspectos psicológicos, que precisam ser considerados numa pessoa sob risco de suicídio, a saber, a ambivalência, a impulsividade e a rigidez/constrição, sendo o pensamento "tudo ou nada" comum às pessoas que não conseguem vislumbrar formas alternativas de solucionar seus problemas.

O motivo chamar a atenção também foi trazido pelos participantes. Segundo eles, a tentativa de suicídio é utilizada com o objetivo de sinalizar que algo não está bem, como um grito de socorro ou desempenhando uma função específica na relação com o outro. Para P7, é "uma maneira de pedir atenção, uma maneira de pedir atenção que ela não consegue pedir de outra maneira". Já P8 vai um pouco mais além:

"Elas tentam porque elas estão fazendo um grito de "olha eu aqui, ainda existo". É um tipo de uma birra, sabe uma criança que quer alguma coisa, mas não consegue verbalizar ou negociar aquilo que ela quer, então ela se joga no chão e esperneia. Eu acho que é essa mesma atitude, só que no adulto".

Estudos apontam que as tentativas de suicídio são comumente entendidas pelos profissionais de saúde como uma tentativa de chamar a atenção (Sampaio \& Boemer, 2000, Silva \& Boemer, 2004; Maliska \&Wallauer, 2012). No relato de P8, a tentativa é comparada ao comportamento infantil da criança, que se joga no chão e esperneia para conseguir o que quer. Nas palavras de Cassorla (1991), tomando como exemplo os casos de mulheres que chegam à emergência por intoxicação medicamentosa, "o rótulo de 'histeria' é rapidamente colocado, e a paciente é enviada para casa ridicularizada ou, na melhor das hipóteses, complacentemente aconselhada com palavras que se crê decorram do bom senso" (p.151).

Com base nisto, Maliska e Wallauer (2012) afirmam existir uma desconsideração do sofrimento psíquico presente por parte de alguns profissionais, questionando assim se esta falta de consideração está relacionada à falta de conhecimento dos aspectos psicológicos e 
emocionais do suicídio. Neste aspecto, ainda que se considere o sofrimento subjacente à tentativa, o entendimento de alguns dos profissionais de saúde não difere muito do que é apontado pelo senso-comum.

Questiona-se se esta forma de compreender o fenômeno poderia ser decorrente da falta de capacitação profissional, cuja oferta é responsabilidade das instituições de saúde, em atividades de educação permanente, como prevê o SUS. Conforme apresentado na descrição dos participantes, apenas 1 (um) profissional recebeu capacitação sobre a temática; logo, o medo de lidar com o paciente suicida e o sentimento de inadequação para atender a demanda, exemplos apontados pelo estudo de Sethi e Uppal (2006), podem ser reflexos desta realidade.

A falta de perspectivas para o futuro é outro motivo apontado pelos participantes. P5 entende que há um "desespero extremo, porque tirar a tua vida é uma coisa, acho que é falta de perspectiva". Já P10 descreve com maiores detalhes, sendo a “... ausência de perspectivas, sob vários aspectos, falta de perspectiva profissional, perspectiva financeira, perspectiva de relacionamento amoroso". Assim, a falta de perspectivas para o futuro é percebida em diversos contextos da vida das pessoas, desde aspectos profissionais, no que se refere a trabalho e emprego, aspectos financeiros, de renda e dinheiro até aspectos de relacionamento afetivo, como por exemplo, conflitos, separações.

Na sequência, estão os conflitos conjugais, também entendidos como motivos para as pessoas tentarem suicídio. Para P6, “... uma grande causa são as brigas conjugais, briga com marido, briga com 0 namorado, briga com o noivo, traição". A fala de P2, a seguir, vai ao encontro da fala acima:

“... então eu já vi situações assim de conflitos conjugais, às vezes até em situações que o parceiro tava querendo sair da relação que a pessoa tenta, isso eu já atendi algumas vezes, aí esse parceiro volta, ela vem, ele cuida, então isso já também atendi".

Entre os tipos de conflitos conjugais, destacam-se as brigas entre casais em geral - marido e mulher, entre namorados, entre noivos. Também são relatadas a traição conjugal e as dificuldades na relação, quando há desejo de separação de um dos cônjuges ou problemas no relacionamento, que seriam "resolvidos" por meio da tentativa de suicídio. Nesta mesma direção, estão os conflitos familiares como pontuado por P12 quando afirma que a pessoa "... às vezes não tem apoio, do cônjuge, ou às vezes tão decepcionados com os filhos".

Pode-se perceber que os conflitos familiares apresentados referem-se à relação mãe e filho, entre cônjuges e ainda outra questão da família 
estendida que reverbere na relação familiar como, por exemplo, doença da família, cuidado de pessoas idosas etc. O Ministério da Saúde (Brasil, 2006) aponta que uma dinâmica familiar conturbada é um fator de risco para tentativas de suicídio, conforme já apresentado. O estudo realizado por Heikkinen e Lönnqvist (1994) observou a relação entre o suicídio e a presença de eventos estressores nos três meses anteriores à morte. Segundo os dados, $80 \%$ dos suicídios apresentavam um evento estressor anterior, com a presença do conflito familiar em $23 \%$ e da separação em $14 \%$ dos casos.

Outro motivo apontado para uma pessoa tentar suicídio refere-se ao "alívio para os outros". Segundo os participantes, as pessoas entendem que ao tentar suicídio estarão fazendo um bem para as pessoas próximas, sejam amigos, sejam familiares, acreditando que os fariam deixar de sofrer ou de precisar se preocupar com elas. Para P3, “... ela [a pessoa que tentou suicídio] pode entender como se fosse ser um alívio pra todo mundo". Já P9 entende que a pessoa se sente incomodando, “... por exemplo, uma pessoa que ah, quer deixar de incomodar, ou uma pessoa que acha que 'ah, eu realmente incomodo'".

E o último motivo pelo qual uma pessoa tenta suicídio observado nas falas dos participantes é a presença de transtornos mentais. De acordo os profissionais, há diferentes transtornos mentais que podem levar a pessoa a atentar contra sua própria vida, como depressão, esquizofrenia, transtorno bipolar de humor etc. O participante 11 (P11) avalia que "geralmente já tem algum transtorno psiquiátrico, já ta tratando uma depressão". Para P5, uma série de transtornos podem ser citados, observados na fala abaixo:

“... ou por doenças mentais mesmo, o cara que é esquizofrênico, acaba atentando contra a vida como se aquilo fosse necessário, mas os que não têm uma doença mental estabelecida, não têm esquizofrenia, não têm transtorno bipolar, enfim".

Além dos transtornos acima listados, também foi trazido que, em geral, os pacientes que tentam suicídio estão fazendo tratamento psiquiátrico ou já trataram algum transtorno, porém não houve continuidade, como se observa na fala de P16, "é mais assim, é mais casos de depressão que não tão tratando ou tão tratando, mas não tão com o controle adequado". Assim, evidencia-se por meio dos dados a corroboração da informação divulgada pela OMS (Bertolote \& Fleischmamm, 2002a), que afirma que mais de $90 \%$ das pessoas que morrem por suicídio eram acometidas por algum transtorno psiquiátrico. 


\section{Conclusão}

A construção dos significados às tentativas de suicídio não é uma tarefa simples, pois é balizada por diferentes aspectos. Assim, este estudo teve como objetivo investigar os significados atribuídos pelos profissionais de saúde que atendem às tentativas de suicídio em urgências e emergências hospitalares. A interlocução entre as subcategorias definição do suicídio, o que as pessoas pensam sobre ele e os motivos pelos quais as pessoas tentam tirar suas vidas revelaram um entrelaçamento semântico que deram um significado particular para o que os participantes pensam sobre o fenômeno, pois, aponta Turato (2005), o significado tem essa função organizadora que dá molde à vida das pessoas.

Evidenciou-se neste estudo que os significados às tentativas foram construídos com base em dois polos: o primeiro apresenta o fenômeno como condição de sofrimento, no qual há uma série de fragilidades e condições desfavoráveis que justificam a tentativa de suicídio. Estas fragilidades e condições levam os profissionais de saúde a adotarem atitudes acolhedoras para com os pacientes atendidos. Já o segundo, ainda que reconheça a condição de sofrimento psíquico, aponta o fenômeno como uma afronta à prática profissional, cujo atendimento não se encaixa às atribuições dos serviços de saúde pesquisados. Isto pôde ser observado no uso às vezes pejorativo do termo chamar a atenção, que rotula o ato bem como desqualifica a demanda enquanto legítima aos serviços.

Considerando a relevância do suicídio às políticas de saúde pública em especial de saúde mental -, este estudo contribui para a produção científica nacional ao se propor pensar a temática em questão. Contudo, entende-se que a busca por respostas está longe de se esgotar. Abre-se assim um leque de possibilidades de olhar o fenômeno, por meio de novos estudos que, por exemplo, relacionem os significados atribuídos às tentativas de suicídio e o impacto destas sobre a prática profissional ou as diferenças de significados atribuídos às tentativas de suicídio por profissionais de saúde mental e os profissionais de saúde em geral. Observou-se no presente estudo, ainda que sem critérios definidos para tal, uma diferença na forma de entender o fenômeno entre os profissionais, que pode vir a ter reflexos tanto positivos quanto negativos no atendimento ao paciente.

Finalmente, é importante pensar em estudos comparativos entre profissionais de saúde e pacientes com histórico de tentativas de suicídio e atendimento, nos serviços de urgência e emergência hospitalares, com vistas a entender se em algum momento estes dialogam e de que forma. Assim, mostra-se premente a necessidade de capacitação profissional acerca da temática, por meio de 
atividades de educação permanente, não se esquecendo da necessidade de pensar em estratégias que consigam prevenir o suicídio e, ao mesmo tempo, ofereçam conhecimentos que levem a um olhar menos pautado em julgamentos e regras morais. Este novo olhar sobre o suicídio possibilitaria que a pessoa em sofrimento psíquico fosse mais bem acolhida em qualquer contexto e, consequentemente, tivesse melhores chances de recuperação e de reinserção social.

\section{Referências}

Bertolote, J. M., \& Fleischmann, A. (2002a). A global perspective in the epidemiology. of suicide. Suicidologi. 7(2), 6-8. Recuperado em 09 de novembro de 2012. Obtido em http: //www.iasp.info/pdf/papers/Bertolote. pdf.

Bertolote, J. M., \& Fleischmann, A. (2002b). Suicide and psychiatric diagnosis: a worldwide perspective. World Psychiatry I(3), 181185. Recuperado em 09 de novembro de 2012. Obtido em http://www.ncbi.nlm.nih.gov/pmc/articles/PMC1489848/.

Bertolote, J. M., Mello-Santos, C. de, \& Botega, N. J. (2010). Detecção do risco de suicídio nos serviços de emergência psiquiátrica. Revista Brasileira de Psiquiatria, 32, 87-95. Recuperado em 18 de outubro de 2012. Obtido em http: //www.scielo.br/scielo. php?pid=S15164446201000060000 $5 \&$ script $=$ sci_arttext

Botega, N. J., Reginato, D. G., Silva, S. V. da., Cais, C. F. da S., Rapeli, C. B., \& Mauro, M. L. F., Stefanello, S. (2005). Nursing personnel attitudes towards suicide: the development of a measure scale. Revista Brasileira de Psiquiatria, 27(4), 315318. Recuperado em 09 de novembro de 2012. Obtido em http: //www.scielo.br/scielo.php?script=sci_arttext\&pid=S15164 4462005000400011

Botega, N. J., Werlang, B.S.G., Cais, C.F.S., \& Macedo, M.M.K. (2006). Prevenção do comportamento suicida. PSICO, 37(3), 213-20. Recuperado em 09 de novembro de 2012. Obtido em http://revistaseletronicas. pucrs.br/ojs/index. php/revistapsico/a rticle/viewfile/ 1442/1130

Brasil (2006). Ministério da Saúde. Organização Pan-Americana de Saúde [OPAS]. Universidade Estadual de Campinas [UNICAMP]. Prevenção de suicídio: manual dirigido a profissionais das equipes de saúde mental. Brasília: Ministério da Saúde.

Brasil (2009). Ministério da Saúde. Secretaria de Vigilância em Saúde. Manual instrutivo de preenchimento da ficha de notificação/investigação de violência doméstica, sexual e outras violências. Brasília: MS. 
Cassorla, R. M. S. (coord.) (1991). Do suicídio: estudos brasileiros. 2a ed. Campinas, SP: Papirus.

Crepaldi, M, A. (2012). Prefácio. In: M. E. Maliska, \& A. Wallauer. Suicídio: um desafio para profissionais de saúde. Florianópolis, SC: Pandion.

Guest, G., Bunce, A., \& Johnson, L. (2006). How Many Interviews Are Enough?: An Experiment with Data Saturation and Variability. Field Methods. February. 18, 59-82.

Heikkinen, M., Aro, H., \& Lönnqvist, J. (1994). Recent life events, social support and suicide. Acta Psychiatrica Scandinavica. Supplementum, 37765-72. Recuperado em 06 de novembro de 2013.

Obtido

em http: //ehis. ebscohost.com/ehost/ detail?vid=7\&sid=42a38cee83b5-47e7-bbb7-

ac44ff221 f98\% 40sessionmgr113\&hid $=102 \&$ bdata $=\mathrm{J}$ mxhbmc9c HQtYnl mc2I0ZT1laG9zdC1saXZI\#db=mdc\&AN =8053369.

Houaiss, A., \& Villar, M. S. (2009) Dicionário Houaiss da Língua Portuguesa. $1^{\underline{a}}$ ed. Rio de Janeiro: Objetiva.

Kishi, Y., Kurosawa, H., Morimura, H., Hatta, K., \& Thurber, S. (2011). Attitudes of Japanese nursing personnel toward patients who have attempted suicide. General Hospital Psychiatry, 33, 393-397. Recuperado em 09 de novembro de 2012.

Obtido

http://www.ncbi.nlm.nih.gov/pubmed/21762837.

Maliska, M. E., \& Wallauer, A. (2012). Suicídio: um desafio para profissionais de saúde. Florianópolis, SC: Pandion.

Muhr, T. (2004). Atlas/ti the knowledge workbench. V 5.0 Quick tour for beginners. Berlin: Scientific Software Development.

Organização Mundial de Saúde [OMS], (2000). Prevenção do suicídio: um manual para médicos clínicos gerais. Genebra: Organização Mundial de Saúde.

Ramos, I. N. B., \& Falcão, E. B. M. (2011). Suicídio: um tema pouco conhecido na formação médica. Revista Brasileira de Educação Médica, 35(4), 507-516. Recuperado em 26 de outubro de $2013 . \quad$ Obtido em http://www.scielo.br/scielo.php?script=sci_arttext\&pid=S010055022011000400010\&lng=en\&tIng=pt. 10.1590/S010055022011000400010.

Resolução no 196 do Conselho Nacional de Saúde (1996). Dispõe sobre diretrizes e normas regulamentadoras de pesquisas envolvendo seres humanos. Recuperado em 09 de novembro de 2012. Obtido em http://www. bioetica.ufrgs. br/res19696. htm.

Sampaio, M. A., \& Boemer, M.R. (2000). Suicídio: um ensaio em busca de um des-velamento do tema. Revista da Escola de Enfermagem da USP, 34(4), 325-331. Recuperado em 06 de novembro de 2013.2 Obtido em: 
http: //www.scielo.br/scielo.php?script=sci_arttext\&pid=S0080$62342000000400002 \& \operatorname{lng}=$ en\&tlng $=$ pt. $10.1590 /$ S008062342000000400002 .

Sethi, S., \& Uppal, S. (2006). Attitudes of clinicians in emergency room towards suicide. Internationa IJ ournal of Psychiatry in Clinical Practice, 10(3), 182-185. Recuperado em 11 de novembro de 2012. Obtido em http: //ehis. ebscohost.com/ehost/pdfviewer/pdfviewer?vid=6\&si $\mathrm{d}=42 \mathrm{a} 38 \mathrm{cee}-83 \mathrm{~b} 5$ - $47 \mathrm{e}$ - $-\mathrm{bbb} 7$ ac44ff221f98\% 40sessionmgr113\&hid $=2$

Silva, V. P. da., \& Boemer, M. R. (2004) . O suicídio em seu mostrarse a profissionais de saúde. Revista Eletrônica de Enfermagem, 06(02), 143-152. Recuperado em 17 de novembro de 2012. Obtido

em http://www.revistas.ufg.br/index.php/fen/article/view/822/952.

Santos, A. C. W.dos, \& Moré, C. L. O. O. (2011). Repercussão da violência na mulher e suas formas de enfrentamento. Paidéia (Ribeirão Preto), 21(49), 227-235. Recuperado em 20 de junho de $2014 . \quad$ Obtido em http: //www.scielo.br/scielo. php?script=sci_arttext\&pid=S0103$863 \times 2011000200010 \&$ lng =en\&tlng=pt. $\quad$ 10.1590/S0103$863 \times 2011000200010$.

Srivastava, M., \& Tiwari R. (2012). A comparative study of attitude of mental health versus nonmental health professionals toward suicide. Indian Journal of Psychological Medicine, 34, 66-69. Recuperado em 09 de novembro de 2012. Obtido em http: //www.ijpm. info/article. asp?issn $=0253$ -

7176; year $=2012$; volume $=34$; issue $=1 ;$ spage $=66$; epage $=69$; aul ast $=$ Srivastava.

Strauss, A., \& Corbin, J. (2008) Pesquisa qualitativa. Técnicas e procedimentos para 0 desenvolvimento de teoria fundamentada. Porto Alegre: Artmed.

Suokas, J., Suominen, K., \& Lönnqvist, J. (2008).Psychological distress and attitudes of emergency personnel towards suicide attempters. Nordic Journal of Psychiatry, 62(2), 144-146. Recuperado em 09 de novembro de 2012. Obtido em http://www.ncbi.nlm.nih.gov/pubmed/18569778.

Turato, E. R. (2005). Métodos qualitativos e quantitativos na área da saúde: definições, diferenças e seus objetos de pesquisa. Revista de Saúde Pública, 39(3), 507-514. Recuperado em 09 de novembro de $2012 . \quad$ Obtido em http://www.scielo.br/scielo. php?cript=sci_arttext\&pid=S003489102005000300025.

Wanderbroocke, A. C. N. de S., \& Moré, C. L. O. O. (2012). Significados de violência familiar contra o idoso na perspectiva de profissionais da Atenção Primária à Saúde. Ciência \& Saúde 
Coletiva, 17(8), 2095-2103. Recuperado em 20 de junho de 2014. Obtido

em http://www.scielo.br/scielo. php?script=sci_arttext\&pid=S1413$81232012000800020 \&$ Ing =pt\&tlng=pt. $\quad 10.1590 /$ S141381232012000800020.

Werlang, B. S. G., Macedo, M. M. K., \& Asnis, N. (2005) Entrevistas retrospectivas: autópsias psicológicas. In: M. M. K. Macedo, \& L. K. Carrasco (Orgs.). (Con)textos de Entrevista: olhares diversos sobre a interação humana. São Paulo, SP: Casa do Psicólogo.

\author{
Endereço para correspondência \\ Ana Paula Araújo de Freitas \\ Departamento de Psicologia \\ Universidade Federal de Santa Catarina \\ Centro de Filosofia e Ciências Humanas - Campus Universitário Trindade \\ Caixa Postal 476, CEP 88.040-970, Santa Catarina - SC, Brasil \\ Endereço eletrônico: anapfreitas2812@gmail.com \\ Lucienne Martins Borges \\ Departamento de Psicologia \\ Universidade Federal de Santa Catarina \\ Centro de Filosofia e Ciências Humanas - Campus Universitário Trindade \\ Caixa Postal 476, CEP 88.040-970, Santa Catarina - SC, Brasil \\ Endereço eletrônico: lucienne.borges@ufsc.br
}

Recebido em: 28/04/2014

Reformulado em: 22/06/2014

Aceito para publicação em: 30/06/2014

\title{
Notas
}

* Mestre em Psicologia pela Universidade Federal de Santa Catarina - Florianópolis, Brasil.

** Doutora em Psicologia. Docente do Departamento de Psicologia, Universidade Federal de Santa Catarina - Florianópolis, Brasil. 